\title{
Background: Tokyo Guidelines for the management of acute cholangitis and cholecystitis
}

\author{
Tadahiro Takada ${ }^{1}$, Yoshifumi Kawarada ${ }^{2}$, Yuji Nimura ${ }^{3}$, Masahiro Yoshida ${ }^{1}$, Toshihiko Mayumi ${ }^{4}$, \\ Mino Sekimoto 5 , Fumihiko Miura ${ }^{1}$, Keita Wada ${ }^{1}$, Masahiko Hirota ${ }^{6}$, Yuichi Yamashita ${ }^{7}$, Masato Nagino ${ }^{3}$, \\ Toshio Tsuyuguchi ${ }^{8}$, Atsushi Tanaka ${ }^{9}$, Yasutoshi Kimura ${ }^{10}$, Hideki Yasuda ${ }^{11}$, Koichi Hirata ${ }^{10}$, \\ Henry A. Pitt ${ }^{12}$, Steven M. Strasberg ${ }^{13}$, Thomas R. Gadacz ${ }^{14}$, Philippus C. Bornman ${ }^{15}$, Dirk J. Gouma ${ }^{16}$, \\ Giulio Belli ${ }^{17}$, and Kui-Hin Liau ${ }^{18}$ \\ ${ }^{1}$ Department of Surgery, Teikyo University School of Medicine, 2-11-1 Kaga, Itabashi-ku, Tokyo 173-8605, Japan \\ ${ }^{2}$ Mie University School of Medicine, Mie, Japan \\ ${ }^{3}$ Division of Surgical Oncology, Department of Surgery, Nagoya University Graduate School of Medicine, Nagoya, Japan \\ ${ }^{4}$ Department of Emergency Medicine and Intensive Care, Nagoya University School of Medicine, Nagoya, Japan \\ ${ }^{5}$ Department of Healthcare Economics and Quality Management, Kyoto University Graduate School of Medicine, School of Public Health, \\ Kyoto, Japan \\ ${ }^{6}$ Department of Gastroenterological Surgery, Kumamoto University Graduate School of Medical Science, Kumamoto, Japan \\ ${ }^{7}$ Department of Surgery, Fukuoka University Hospital, Fukuoka, Japan \\ ${ }^{8}$ Department of Medicine and Clinical Oncology, Graduate School of Medicine, Chiba University, Chiba, Japan \\ ${ }^{9}$ Department of Medicine, Teikyo University School of Medicine, Tokyo, Japan \\ ${ }^{10}$ First Department of Surgery, Sapporo Medical University School of Medicine, Sapporo, Japan \\ ${ }^{11}$ Department of Surgery, Teikyo University Chiba Medical Center, Chiba, Japan \\ ${ }^{12}$ Department of Surgery, Indiana University School of Medicine, Indianapolis, USA \\ ${ }^{13}$ Department of Surgery, Washington University in St Louis and Barnes-Jewish Hospital, St Louis, USA \\ ${ }^{14}$ Department of Gastrointestinal Surgery, Medical College of Georgia, Georgia, USA \\ ${ }^{15}$ Division of General Surgery, University of Cape Town, Cape Town, South Africa \\ ${ }^{16}$ Department of Surgery, Academic Medical Center, Amsterdam, The Netherlands \\ ${ }^{17}$ General and HPB Surgery, Loreto Nuovo Hospital, Naples, Italy \\ ${ }^{18}$ Department of Surgery, Tan Tock Seng Hospital / Hepatobiliary Surgery, Medical Centre, Singapore
}

\begin{abstract}
There are no evidence-based-criteria for the diagnosis, severity assessment, of treatment of acute cholecysitis or acute cholangitis. For example, the full complement of symptoms and signs described as Charcot's triad and as Reynolds' pentad are infrequent and as such do not really assist the clinician with planning management strategies. In view of these factors, we launched a project to prepare evidence-based guidelines for the management of acute cholangitis and cholecystitis that will be useful in the clinical setting. This research has been funded by the Japanese Ministry of Health, Labour, and Welfare, in cooperation with the Japanese Society for Abdominal Emergency Medicine, the Japan Biliary Association, and the Japanese Society of Hepato-Biliary-Pancreatic Surgery. A working group, consisting of 46 experts in gastroenterology, surgery, internal medicine, emergency medicine, intensive care, and clinical epidemiology, analyzed and examined the literature on patients with cholangitis and cholecystitis in order to produce evidence-based guidelines. During the investigations we found that there was a lack of high-level evidence, for treatments, and the working group formulated the guidelines by obtaining consensus, based on evidence categorized by level, according to the Oxford Centre for Evidence-Based Medicine Levels of Evidence of May 2001 (version 1). This
\end{abstract}

Offprint requests to: $\mathrm{T}$. Takada

Received: May 31, 2006 / Accepted: August 6, 2006 work required more than 20 meetings to obtain a consensus on each item from the working group. Then four forums were held to permit examination of the Guideline details in Japan, both by an external assessment committee and by the working group participants (version 2). As we knew that the diagnosis and management of acute biliary infection may differ from country to country, we appointed a publication committee and held 12 meetings to prepare draft Guidelines in English (version 3 ). We then had several discussions on these draft guidelines with leading experts in the field throughout the world, via e-mail, leading to version 4. Finally, an International Consensus Meeting took place in Tokyo, on 1-2 April, 2006, to obtain international agreement on diagnostic criteria, severity assessment, and management.

Key words Cholangitis - Cholecystitis - Charcot's triad . Reynold's pentad · Biliary drainage

\section{Introduction}

No guidelines focusing on the management of biliary infection (cholangitis and cholecystitis) have previously been published, and no worldwide criteria exist for diagnostic and severity assessment. "Charcot's triad"1 is still used for the diagnosis of acute cholangitis. How- 
ever, these criteria were first proposed in 1877 (level 4), more than 100 years ago. Here, and throughout the series, levels of evidence are stated for referenced articles in accordance with the Oxford Centre for EvidenceBased Medicine Levels of Evidence of May 2001 (see Table 1 ). However only $50 \%-70 \%$ of cholangitis patients present clinically with Charcot's triad. ${ }^{2-8}$ In addition, Murphy's sign ${ }^{9}$ (level 5) is useful (sensitivity of $50 \%-70 \%$ and specificity of $79 \%-96 \%$ ) in diagnosing cholecystitis, and this sign is widely used in every country. Moreover, as many of the symptoms and concepts of these diseases referred to in textbooks and reference books vary from those originally stated, the issue of worldwide criteria is problematic. In view of these unfavorable situations, we considered it necessary to clarify the definitions, concepts of disease, and treatment methods for acute cholangitis and acute cholecystitis and establish universal criteria that can be widely recognized and used.

A working group to establish practical Guidelines for the Management of Cholangitis and Cholecystitis was organized in 2003 (chief researcher, Tadahiro Takada). This project was funded by a grant from the Japanese Ministry of Health, Labour, and Welfare, and was supported by the Japanese Society for Abdominal Emergency Medicine, the Japan Biliary Association, and the Japanese Society of Hepato-Biliary-Pancreatic Surgery. The working group consisted of physicians engaged in gastroenterology, internal medicine, surgery, emergency medicine, intensive care, and clinical epidemiology as the main members, and they started the work to prepare the Guidelines.

As the research progressed, the group was faced with the serious problem that high-level evidence regarding the treatment of acute biliary infection is poor. Therefore, an exective committee meeting was convened, and the committee came to the following decision: the Guidelines would be evidence-based in general, but areas without evidence or with poor evidence (such as diagnosis and severity assessment) should be completed by obtaining high-level consensus among experts worldwide.

We established a publication committee and held 12 meetings to prepare draft Guidelines in English (version 3). Then we had several discussions on these draft Guidelines with leading experts in the field throughout the world, via e-mail, leading to version 4. Finally, an International Consensus Meeting took place in Tokyo, on 1-2 April, 2006, to obtain international agreement on diagnostic criteria, severity assessment, and management.

We now publish the "Tokyo Guidelines for the Management of Cholangitis and cholecystitis". These Guidelines consist of 13 articles, including "Discussion" sections containing comments of attendees at the con- sensus conference and analyses of audience voting at the meeting.

We hope that these Guidelines will help their users to give optimal treatment according to their own specialty and capability, and thus provide their patients with the best medical treatment.

\section{Background of Tokyo Guidelines}

Biliary infections (acute cholangitis and cholecystitis) require appropriate management in the acute phase. Serious acute cholangitis may be lethal unless it is appropriately managed in the acute phase. On the other hand, although various diagnostic and treatment methodologies have been developed in recent years, they have not been assessed objectively and none of them has been established as a standard method for the management of these diseases. We carried out an extensive review of the English-language literature and found that there was little high-level evidence in this field, and no systematically described practical manual for the field. Most importantly, there are no standardized diagnostic criteria and severity assessments for acute cholangitis and cholecystitis, therefore, we would like to establish standards for these items. The Tokyo Guidelines include evidence-based medicine and reflect the international consensus obtained through earnest discussions among professionals in the field on 1-2 April, 2006, at the Keio Plaza Hotel, Tokyo, Japan. Concerning the definitions in the practice guidelines, we have applied to the Japanese Institute of Medicine: Committee to Advise the Public Health Service on Clinical Practice Guidelines, to approve the systematically developed Guidelines to assist practioner and patient decisions about appropriate healthcare for specific clinical circumstances.

\section{Notes on the use of the Guidelines}

The Guidelines are evidence-based, with the grade of recommendation also based on the evidence. The Guidelines also present the diagnostic criteria for and severity assessment of acute biliary infection. As the Guidelines address so many different subjects, indices are included at the end for the convenience of readers.

The practice Guidelines promulgated in this work do not represent a standard of practice. They are suggested plans of care, based on best available evidence and the consensus of experts, but they do not exclude other approaches as being within the standard of practice. For example, they should not be used to compel adherence to a given method of medical management, which meth- 
od should be finally determined after taking account of the conditions at the relevant medical institution (staff levels, experience, equipment, etc.) and the characteristics of the individual patient. However, responsibility for the results of treatment rests with those who are directly engaged therein, and not with the consensus group. The doses of medicines described in the text of the Guidelines are for adult patients.

\section{Methods of formulating the guidelines}

With evidence-based medicine (EBM) as a core concept, the Guidelines were prepared by the Research Group on the Preparation and Diffusion of Guidelines for the Management of Acute Cholangitis and Acute Cholecystitis (chief researcher, Tadahiro Takada), under the auspices of the Japanese Ministry of Health, Labour, and Welfare, and the Working Group for Guideline Preparation, whose members were selected from experts in abdominal emergency medicine and epidemiology by the Japanese Society for Abdominal Emergency Medicine, the Japan Biliary Association, and the Japanese Society of Hepato-Biliary-Pancreatic Surgery.

In principle, the preparation of the Guidelines progressed with the systematic search, collection, and assessment of references for the objective extraction of evidence. Next, the External Assessment Committee examined the Guidelines. Then we posted the draft guidelines on our website and had four open symposia, bginning in September 2004, to gain feedback for further review. Subsequently, a Publication Committee was set up, and this committee had 12 meetings to prepare draft Guidelines.

Re-examination of the draft Guidelines was then performed, via e-mail, with experts on cholangitis and cholecystitis throughout the world. After final agreement was reached at the International Consensus Meeting, held in Tokyo in April 2006, "the Tokyo Guidelines for the Management of Acute Cholangitis and Cholecystitis" were completed.

\section{The process of extending the literature search}

The literature was selected as follows: Using "cholangitis" and "cholecystitis" as the medical subject heading (MeSH; explode) or the key search words, approximately 17200 items were selected from Medline (Ovid; 1966 to June 2003). These articles were subjected to a further screening with "human" as the "limiting word". This screening provided 9618 items in English and in Japanese. A further 7093 literature publications were obtained from the Japana Centra Revuo Medicina (internet version), using "cholangitis", "cholecystitis", and "biliary infection" as the key words, with further screening with "human" as the "limiting word". This process provided 6141 items. After the titles and abstracts of a total of 15759 works were examined by two committee members, 2494 were selected for a careful examination of their full texts.

Other literature quoted in these selected works, together with works suggested by the specialist committee members, were included in the examination.

To evaluate each article, a STARD (standards for reporting of diagnostic accuracy) checklist (Table 1) ${ }^{12}$ was considered important. The purpose of this checklist is to evaluate the format and study process, in order to improve the accuracy and completeness of the reporting of studies of diagnostic accuracy.

However, the STARD checklist is not suitable for classifying various categories (e.g., therapy, prevention, etiology, harm, prognosis, diagnosis, differential diagnosis, economic and decision analysis) and levels of evidence. Therefore, in the Guidelines, the science-based classification used by the Cochrane Library (Table 2) was adopted.

The evidence obtained from each item of reference was evaluated in accordance with the science-based classification used by the Cochrane Library (Table 2), and the quality of evidence for each parameter associated with the diagnosis and treatment of acute biliary infection was determined. As stated above, the level of evidence presented by each article was determined in accordance with the Oxford Centre for Evidence-Based Medicine Levels of Evidence (May 2001), prepared by Phillips et al. ${ }^{13}$ (Table 2). The terms used in the categories are explained in the footnote to Table 2.

\section{Categories of evidence and grading of recommendations}

Based on the results obtained from these procedures, grades of recommendation were determined, according to the system for ranking recommendations in clinical guidelines ${ }^{14-16}$ shown in Table 3, and mentioned, as required, in the text of the Guidelines. The grades of recommendation in the Guidelines are based on the Kish ${ }^{14}$ method of classification and others. ${ }^{15,16}$ Recommendations graded "A" (that is, "do it") and "B" (that is, "probably do it"), are based on a high level of evidence, whereas those graded " $\mathrm{D}$ " (that is, "probably don't do it") or "E" (that is, "don't do it") reflect a low level of evidence.

Acknowledgments. We would like to express our deep gratitude to the Japanese Society for Abdominal Emergency Medicine, the Japan Biliary Association, and the Japanese Society of Hepato-Biliary-Pancreatic Surgery, who provided us with great support and guidance in the preparation of the Guidelines. This process was conducted as part of the project for the Preparation and 
Table 1. STARD checklist for the reporting of studies of diagnostic accuracy

\begin{tabular}{|c|c|c|c|}
\hline $\begin{array}{l}\text { Section and } \\
\text { topic }\end{array}$ & Item no. & & $\begin{array}{c}\text { On page } \\
\text { no. }\end{array}$ \\
\hline $\begin{array}{l}\text { Title/Abstract/ } \\
\text { Key words }\end{array}$ & 1 & $\begin{array}{l}\text { Identify the article as a study of diagnostic accuracy (recommend MeSH heading } \\
\text { "sensitivity and specificity") }\end{array}$ & \\
\hline Introduction & 2 & $\begin{array}{l}\text { State the research questions or study aims, such as estimating diagnostic accuracy } \\
\text { or comparing accuracy between tests or across participant groups }\end{array}$ & \\
\hline Methods & & Describe & \\
\hline \multirow[t]{4}{*}{ Participants } & 3 & $\begin{array}{l}\text { The study population: the inclusion and exclusion criteria, setting and locations } \\
\text { where the data were collected }\end{array}$ & \\
\hline & 4 & $\begin{array}{l}\text { Participant recruitment: was recruitment based on presenting symptoms, results } \\
\text { from previous tests, or the fact that the participants had received the index tests } \\
\text { or the reference standard? }\end{array}$ & \\
\hline & 5 & $\begin{array}{l}\text { Participant sampling: was the study population a consecutive series of participants } \\
\text { defined by the selection criteria in items } 3 \text { and } 4 \text { ? If not, specify how participants } \\
\text { were further selected }\end{array}$ & \\
\hline & 6 & $\begin{array}{l}\text { Data collection: was data collection planned before the index test and reference } \\
\text { standard were performed (prospective study) or after (retrospective study)? }\end{array}$ & \\
\hline \multirow[t]{5}{*}{ Test methods } & 7 & The reference standard and its rationale & \\
\hline & 8 & $\begin{array}{l}\text { Technical specifications of material and methods involved, including how and when } \\
\text { measurements were taken, and/or cite references for index tests and reference } \\
\text { standard }\end{array}$ & \\
\hline & 9 & $\begin{array}{l}\text { Definition of and rationale for the units, cutoffs, and/or categories of the results of } \\
\text { the index tests and the reference standard }\end{array}$ & \\
\hline & 10 & $\begin{array}{l}\text { The number, training, and expertise of the persons executing and reading the index } \\
\text { tests and the reference standard }\end{array}$ & \\
\hline & 11 & $\begin{array}{l}\text { Whether or not the readers of the index tests and reference standard were blind } \\
\text { (masked) to the results of the other test, and describe any other clinical } \\
\text { information available to the readers }\end{array}$ & \\
\hline \multirow[t]{2}{*}{$\begin{array}{l}\text { Statistical } \\
\text { methods }\end{array}$} & 12 & $\begin{array}{l}\text { Methods for calculating or comparing measures of diagnostic accuracy, and the } \\
\text { statistical methods used to quantify uncertainty (e.g., } 95 \% \text { confidence intervals) }\end{array}$ & \\
\hline & 13 & Methods for calculating test reproducibility, if done & \\
\hline Results & & Report & \\
\hline \multirow[t]{3}{*}{ Participants } & 14 & When study was done, including beginning and ending dates of recruitment & \\
\hline & 15 & $\begin{array}{l}\text { Clinical and demographic characteristics of the study population (e.g., age, sex } \\
\text { spectrum of presenting symptoms, comorbidity, current treatments, recruitment } \\
\text { centers) }\end{array}$ & \\
\hline & 16 & $\begin{array}{l}\text { The number of participants satisfying the criteria for inclusion that did or did not } \\
\text { undergo the index tests and/or the reference standard; describe why participants } \\
\text { failed to receive either test (a flow diagram is strongly recommended) }\end{array}$ & \\
\hline \multirow[t]{4}{*}{ Test results } & 17 & $\begin{array}{l}\text { Time interval from the index tests to the reference standard, and any treatment } \\
\text { administered between }\end{array}$ & \\
\hline & 18 & $\begin{array}{l}\text { Distribution of severity of disease (define criteria) in those with the target } \\
\text { condition; other diagnoses in participants without the target condition }\end{array}$ & \\
\hline & 19 & $\begin{array}{l}\text { A cross-tabulation of the results of the index tests (including indeterminate and } \\
\text { missing results) by the results of the reference standard; for continuous results, } \\
\text { the distribution of the test results by the results of the reference standard }\end{array}$ & \\
\hline & 20 & Any adverse events from performing the index tests or the reference standard & \\
\hline \multirow[t]{4}{*}{ Estimates } & 21 & $\begin{array}{l}\text { Estimates of diagnostic accuracy and measures of statistical uncertainty (e.g., 95\% } \\
\text { confidence intervals) }\end{array}$ & \\
\hline & 22 & $\begin{array}{l}\text { How indeterminate results, missing responses, and outliers of the index tests } \\
\text { were handled }\end{array}$ & \\
\hline & 23 & $\begin{array}{l}\text { Estimates of variability of diagnostic accuracy between subgroups of participants, } \\
\text { readers, or centers, if done }\end{array}$ & \\
\hline & 24 & Estimates of test reproducibility, if done & \\
\hline Discussion & 25 & Discuss the clinical applicability of the study findings & \\
\hline
\end{tabular}

Adapted from reference 12

$\mathrm{MeSH}$, medical subject heading; STARD, standards for reporting of diagnostic accuracy 


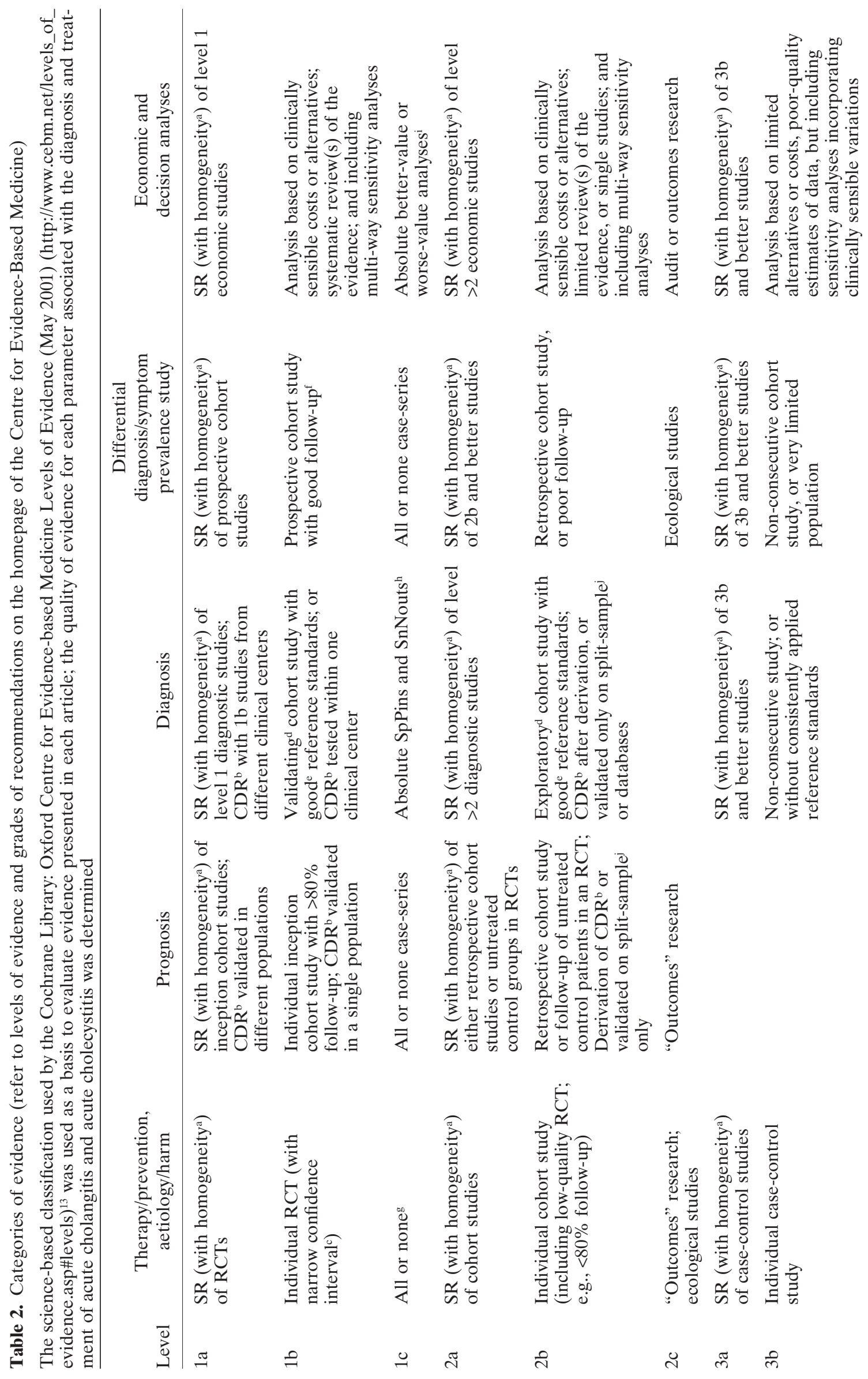




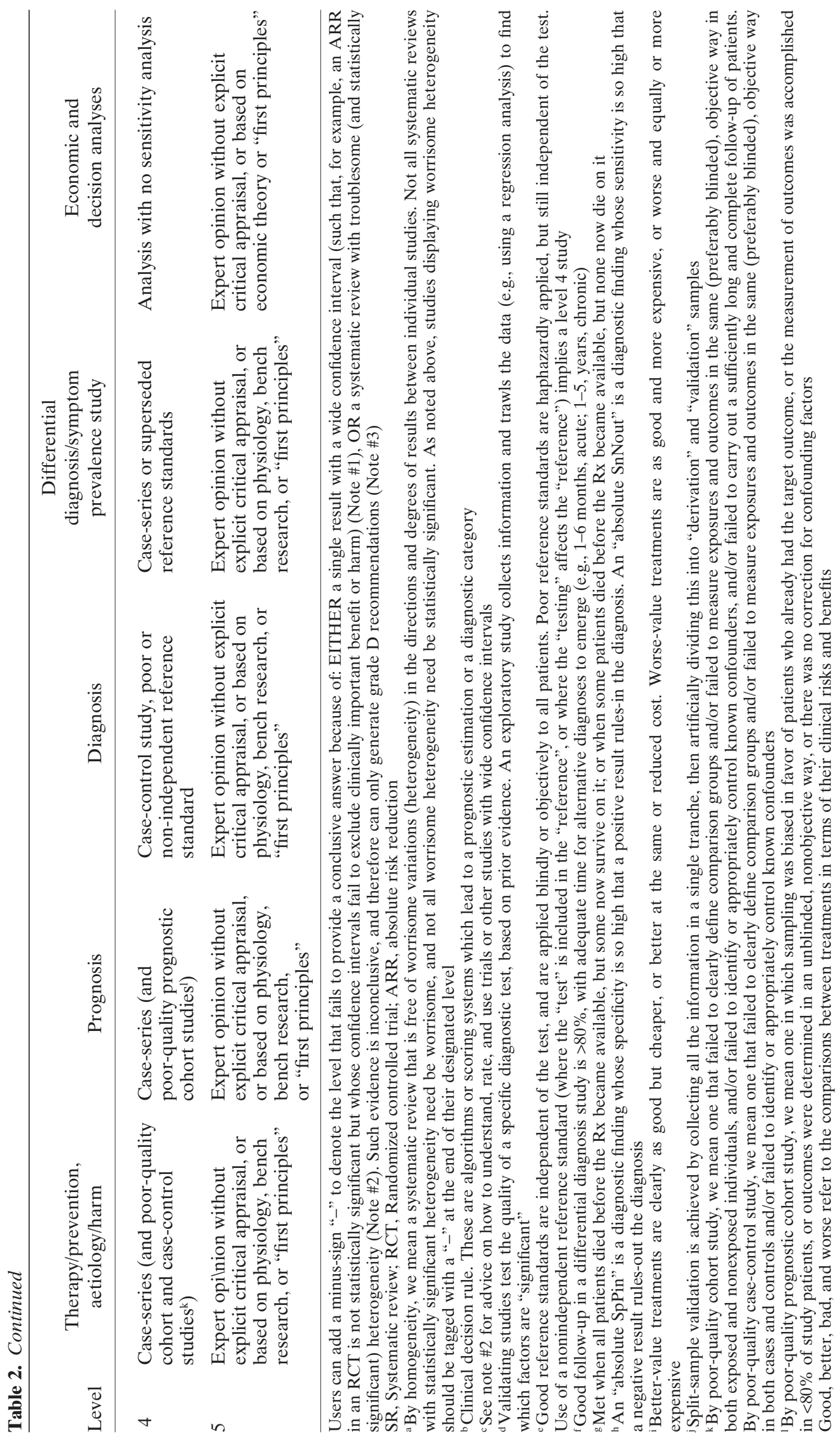


Table 3. Grading system for ranking recommendations in clinical guidelines ${ }^{14-16}$

Grade of recommendation

\begin{tabular}{ll}
\hline A & Good evidence to support a recommendation for use \\
B & Moderate evidence to support a recommendation for use \\
C & Poor evidence to support a recommendation, or the effect may not exceed the adverse effects \\
and/or inconvenience (toxicity, interaction between drugs and cost) & Moderate evidence to support a recommendation against use \\
E & Good evidence to support a recommendation against use
\end{tabular}

Diffusion of Guidelines for the Management of Acute Cholangitis (H-15-Medicine-30), with a research subsidy for fiscal 2003 and 2004 (Integrated Research Project for Assessing Medical Technology) sponsored by the Japanese Ministry of Health, Labour, and Welfare.

We also truly appreciate the panelists who cooperated with and contributed significantly to the International Consensus Meeting held in Tokyo on April 1 and 2, 2006.

\section{References}

1. Charcot M. De la fievre hepatique symptomatique. Comparaison avec la fievre uroseptique. Lecons sur les maladies du foie des voies biliares et des reins. Pairs: Bourneville et Sevestre; 1877. p. $176-85$.

2. Boey JH, Way LW. Acute cholangitis. Ann Surg 1980;191:264-70. (level 4)

3. O'Connor MJ, Schwartz ML, McQuarrie DG, Sumer HW. Acute bacterial cholangitis: an analysis of clinical manifestation. Arch Surg 1982;117:437-41. (level 4)

4. Lai EC, Tam PC, Paterson IA, Ng MM, Fan ST, Choi TK, et al. Emergency surgery for severe acute cholangitis. The high-risk patients. Ann Surg 1990;211:55-9. (level 4)

5. Haupert AP, Carey LC, Evans WE, Ellison EH. Acute suppurative cholangitis. Experience with 15 consecutive cases. Arch Surg 1967;94:460-8. (level 4)

6. Csendes A, Diaz JC, Burdiles P, Maluenda F, Morales E. Risk factors and classification of acute suppurative cholangitis. $\mathrm{Br} \mathrm{J}$ Surg 1992;79:655-8. (level 2b)

7. Welch JP, Donaldson GA. The urgency of diagnosis and surgical treatment of acute suppurative cholangitis. Am J Surg 1976;131: 527-32. (level 4)

8. Chijiiwa K, Kozaki N, Naito T, Kameoka N, Tanaka M. Treatment of choice for choledocholithiasis in patients with acute obstructive suppurative cholangitis and liver cirrhosis. Am J Surg 1995;170:356-60. (level 2b)

9. Murphy JB. The diagnosis of gall-stones. Am Med News 82:825-33.

10. Eskelinen M, Ikonen J, Lipponen P. Diagnostic approaches in acute cholecystitis; a prospective study of 1333 patients with acute abdominal pain. Theor Surg 1993;8:15-20. (level 2b)

11. Trowbridge RL, Rutkowski NK, Shojania KG. Does this patient have acute cholecystitis? JAMA 289:80-6. (level 3b)
12. Bossuyt PM, Reitsma JB, Bruns DE, Glaziou CA, Irwig LM, Lijmer JG, et al., for the STARD Group; STARD checklist for the reporting of studies of diagnostic accuracy. Ann Int Med 2003;138:40-E-45.

13. Phillips B, et al. Levels of evidence and grades of recommendations on the homepage of the Centre for Evidence-Based Medicine (http://cebm.jr2.ox.ac.uk/docs/levels.html) 2001 revised version.

14. Kish MA; Infectious Diseases Society of America. Guide to development of practice guidelines. Clin Infect Dis 2001;32:851-4.

15. Mayumi T, Ura H, Arata S, Kitamura N, Kiriyama I, Shibuya K, et al. Evidence-based clinical practice guidelines for acute pancreatitis: proposals. J Hepatobiliary Pancreat Surg 2002;9:413-22.

16. Takada T, Hirata K, Mayumi T, Yoshida M, Sekimoto M, Hirota M, et al. JPN Guidelines for the management of acute pancreatitis: the cutting edge. J Hepatobiliary Pancreat Surg 2006;13:2-6.

\section{Discussion at the Tokyo International Consensus Meeting}

Tadahiro Takada (Japan): "Dr. Strasberg, please explain the difference between a 'Guidelines' and 'Standards' in your mind?"

Steven Strasberg (USA): “To me, 'guidelines' represent a suggested course of action based on available evidence. They do not imply that other courses of action are below an acceptable level of care. Practice 'standards' are different, in that they imply that actions other than those listed as acceptable practice standards are below the level of acceptable care. It is particularly true that, in an area in which high levels of evidence are not available, that guidelines are not construed to be standards. Reliance on expert opinion to form guidelines may be useful, but even a consensus of experts may not be correct. For this reason a statement of the following type should be inserted in the introduction. 'The practice guidelines promulgated in this work do not represent a standard of practice. They are a suggested plan of care based on best available evidence and a consensus of experts, but they do not exclude other approaches as being within the standard of practice'." 


\title{
The Members of Organizing Committee and Contributors for Tokyo Guidelines
}

\author{
Members of the Organizing Committee of Tokyo Guidelines for the Management of Acute Cholangitis \\ and Cholecystitis \\ T. TAKADA Department of Surgery, Teikyo University School of Medicine, Tokyo, Japan \\ Y. Nimura Division of Surgical Oncology, Department of Surgery, Nagoya University, Graduate School of \\ Medicine, Nagoya, Japan \\ Y. Kawarada Mie University, Mie, Japan \\ K. Hirata First Department of Surgery, Sapporo Medical University School of Medicine, Sapporo, \\ Japan \\ H. YAsuda $\quad$ Department of Surgery, Teikyo University Chiba Medical Center, Chiba, Japan \\ Y. Yamashita Department of Surgery, Fukuoka University School of Medicine, Fukuoka, Japan \\ Y. Kimura First Department of Surgery, Sapporo Medical University School of Medicine, Sapporo, \\ Japan \\ M. Sекімото Department of Healthcare Economics and Quality Management, Kyoto University Graduate \\ School of Medicine, Kyoto, Japan \\ T. Tsuyuguchi Department of Medicine and Clinical Oncology, Graduate School of Medicine, Chiba Univer- \\ sity, Chiba, Japan \\ M. NAGino Division of Surgical Oncology, Department of Surgery, Nagoya University Graduate School of \\ Medicine, Nagoya, Japan \\ M. Нirota Department of Gastroenterological Surgery, Kumamoto University Graduate School of Medical \\ Sciences, Kumamoto, Japan \\ T. Mayumi Department of Emergency Medicine and Critical Care, Nagoya University Graduate School of \\ Medicine, Nagoya, Japan \\ F. MiURA Department of Surgery, Teikyo University School of Medicine, Tokyo, Japan \\ M. Yoshida Department of Surgery, Teikyo University School of Medicine, Tokyo, Japan
}

\section{Advisors and International Members of Tokyo Guidelines for the Management of Acute Cholangitis and Cholecystitis}

N. Abe

S. ARII

J. BELGHITI

G. BELli

P.C. BornMAN

M.W. BÜCHLER

A.C.W. Chan

M.F. CHEN

X.P. CHEN

E.D. Santibanes

C. Dervenis

S. DOWAKI

S.T. FAN

H. FuJII

T.R. GADACZ

D.J. Gouma
Department of Surgery, Kyorin University School of Medicine, Tokyo, Japan

Department of Hepato-Biliary-Pancreatic / General Surgery, Tokyo Medical and Dental University, Tokyo, Japan

Department of Digestive Surgery \& Transplantation, Hospital Beaujon, Clichy, France

Department of General and HPB Surgery, Loreto Nuovo Hospital, Naples, Italy

Division of General Surgery, University of Cape Town, Cape Town, South Africa

Department of General Surgery, University of Heidelberg, Germany

Director Endoscopy Centre, Specialist in General Surgery, Minimally Invastive Surgery Centre

Chang Gung Memorial Hospital, Chang Gung Medical University, Taiwan

Department of Surgery, Tongji Hunter College, Tongji Hospital Hepatic Surgery Centre, China

HPB and Liver Transplant Unit, Hospital Italiano de Buenos Aires, Argentina

First Department of Surgery, Agia Olga Hospital, Greece

Department of Digestive Surgery, Tokai University Tokyo Hospita, Kanagawa, Japan

Department of Surgery, The University of Hong Kong Medicak Centre, Queen Mary Hospital, Hong Kong

$1^{\text {st }}$ Department of Surgery, University of Yamanashi Faculty of Medicine, Yamanashi, Japan

Gastrointestinal Surgery, Medical College of Georgia, USA

Department of Surgery, Academic Medical Center, Amsterdam, The Netherlands 
S.C. Hilvano

S. IsAJI

M. Iто

T. Kanematsu

N. KANO

C.G. KeR

M.H. KIM

S.W. KIM

W. KimURA

S. KitAno

E.C.S. LaI

J.W.Y. LAU

K.H. LiAU

S. MiYAKAWA

K. MiYazaKI

H. NAGAI

T. NAKAGOHRI

H. Neuhaus

T. ОнтА

К. Окамото

R.T. PAdBury

B.B. PhilipPI

H.A. PitT

M. RYU

V. Sachakul

M. SHIMAZU

T. SHIMIZU

K. SHIRATORI

H. SINGH

J.S. SolOMKIN

S.M. StRASBERG

K. Suto

A.N. SupE

M. TADA

S. TAKAO

H. TAKIKAWA

M. TANAKA

S. TASHIRO

S. TAZuma

M. UNNO

G. Wanatabe
Department of Surgery, College of Medical \& Philippine General Hospital, Philippines

Department of Hepato-Biliary-Pancreatic Surgery, Mie University Graduate School of Medicine, Mie, Japan

Department of Surgery, Fujita Health University, Nagoya, Japan

Second Department of Surgery, Nagasaki University Graduate School of Biomedical Sciences, Nagasaki, Japan

Special Adviser to the President, Chairman of Department of Surgery and Director of Endoscopic Surgical Center, Kameda Medical Center, Chiba, Japan

Division of HPB Surgery, Yuan's General Hospital, Taiwan

Department of Internal Medicine, Asan Medical Center, University of Ulsan College of Medicine, Korea

Department of Surgery, Seoul National University College of Medicine, Korea

First Department of Surgery, Yamagata University Faculty of Medicine, Yamagata, Japan

First Department of Surgery, Oita University Faculty of Medicine, Oita, Japan

Pedder Medical Partners, Hong Kong

Faculty of Medicine, The Chinese University of Hong Kong, Hong Kong

Department of Surgery, Tan Tock Seng Hospital/Hepatobiliary Surgery, Singapore

Department of Surgery, Fujita Health University, Nagoya, Japan

Department of Surgery, Saga Medical School, Saga University Faculty of Medicine, Saga,

Japan

Department of Surgery, Jichi Medical School, Tokyo, Japan

Department of Surgery, National Cancer Center Hospital East, Chiba, Japan

Internal Medicine Evangelisches Krankenhaus Dusseldorf, Germany

Department of Digestive Surgery, Kanazawa University Hospital, Ishikawa, Japan

First Department of Surgery, School of Medicine, University of Occupational and Environmental Health, Fukuoka, Japan

Department of Surgery, The Flinders University of South Australia GPO, Australia)

Department of Surgery, University of Indonesia, Cipto Mangunkusumo National Hospital, Jakarta, Indonesia

Department of Surgery, Indiana University School of Medicine, USA

Chiba Cancer Center, Chiba, Japan

Department of Surgery, Phramongkutklao College of Medecine, Thailand

Department of Surgery, Keio University School of Medicine, Tokyo, Japan

Department of Surgery, Nagaoka Chuo General Hospital, Niigata, Japan

Department of Digestive tract internal medicine, Tokyo Women's Medical University, Tokyo, Japan

Department of HPB Surgery, Selayang Hospital, Malaysia

Department of Surgery, University of Cincinnati College of Medicine Cincinnati, Ohio, USA

Department of Surgery, Washington University in St Louis and Barnes-Jewish Hospital, USA

Department of Surgery, Yamagata University Faculty of Medicine, Yamagata, Japan

Department of Surgical Gastroenterology, Seth G S Medical College and K E M Hospital, India

Department of Digestive tract internal medicine, Graduate School of Medicine University of Tokyo, Tokyo, Japan

Research Center for life science resources, Kagoshima University Faculty of Medicine, Kagoshima, Japan

Teikyo University School of Medicine, Tokyo, Japan

Department of Surgery and Oncology, Graduate School of Medical Sciences Kyushu University, Fukuoka, Japan

Shikoku Central Hospital, Ehime, Japan

Department of Primary Care Medicine, Hiroshima University School of Medicine, Hiroshima, Japan

Department of Digestive Surgery, Tohoku University Graduate School of Medicine, Miyagi, Japan

Department of Digestive Surgery, Toranomon Hospital Tokyo, Tokyo, Japan 
J.A. Windsor Department of General Surgery, Auckland Hospital, New Zealand

H. Yamaue Second Department of Surgery, Wakayama Medical University School of Medicine, Wakayama, Japan

\section{Working group of the Guidelines for the Management of Acute Cholangitis and Cholecystitis}

M. Mayumi Department of Emergency Medicine and Critical Care, Nagoya University School of Medicine,

M. YosHidA

T. SAKAI

N. ABE

М. Іто

H. UENo

M. UNNO

Y. KIMURA

M. Sекімото

S. DowAKI

N. NAGO

J. HatA

M. Hirota

F. MiURA

Y. Ogura

A. TANAKA

T. Tsuyuguchi

M. NAGino

K. Suto

Т. ОнтА

I. ENDO

Y. YAMASHITA

S. YoKomuro

Nagoya, Japan

Department of Surgery, Teikyo University School of Medicine, Tokyo, Japan

Kyoto Katsura Hospital, General Internal Medicine, Kyoto, Japan

Department of Surgery, Kyorin University School of Medicine, Tokyo, Japan

Department of surgery, Fujita-Health University, Aichi, Japan

Department of Emergency and Critical Care Medicine, Graduate School of Medicine, Chiba University, Chiba, Japan

Department of Surgery, Tohoku University Graduate School of Medical Science, Sendai, Japan

First Department of Surgery, Sapporo Medical University School of Medicine, Sapporo, Japan

Department of Healthcare Economics and Quality Management, Kyoto University Graduate School of Medicine, Kyoto, Japan

Department of Surgery, Tokai University School of Medicine, Kanagawa, Japan

Japanese Association for Development of Community Medicine, Yokosuka Uwamachi Hospital, Yokosuka, Japan

Department of Laboratory Medicine, Kawasaki Medical School, Kurashiki, Japan

Department of Gastroenterological Surgery, Kumamoto University Graduate School of Medical

Sciences, Kumamoto, Japan

Department of Surgery, Teikyo University School of Medicine, Tokyo, Japan

Department of Pediatric Surgery, Nagoya University School of Medicine, Nagoya, Japan

Department of Medicine, Teikyo University School of Medicine, Tokyo, Japan

Department of Medicine and Clinical Oncology, Graduate School of Medicine, Chiba University, Chiba, Japan

Division of Surgical Oncology, Department of Surgery, Nagoya University Graduate School of Medicine, Nagoya, Japan

Department of Gastroenterological and General Surgery, Course of Organ Functions and Controls, Yamagata University School of Medicine, Yamagata, Japan

Department of Surgery, Institute of Gastroenterology, Tokyo Women's Medical University, Tokyo, Japan

Department of Gastroenterological Surgery, Yokohama City University Graduate School of Medicine, Yokohama, Japan

Department of Surgery, Fukuoka University Hospital, Fukuoka, Japan

Nippon Medical School, Graduate School of Medicine Surgery for Organ Function and Biological Regulation, Tokyo, Japan

\section{Members of the External Evaluation Committee}

T. FUKUI

Y. IMANAKA

Y. SumiYama

T. SHIMIZU

H. SAISHO

К. Окамото
St. Luke's International Hospital, Tokyo, Japan

Department of Healthcare Economics and Quality Management, Kyoto University Graduate School of Medicine, Kyoto, Japan

Third Department of Surgery, Toho University School of Medicine, Tokyo, Japan

Department of Surgery, Nagaoka chuo General Hospital, Nagaoka, Japan

Department of Medicine and Clinical Oncology, Graduate School of Medicine, Chiba University, Chiba, Japan

First Department of Surgery, School of Medicine, University of Occupational and Environmental Health, Kitakyushu, Japan 